lesion came from several vessels lying in level IV of the neck, immediately lateral to the internal jugular vein; these were ligated.

The patient made an uneventful recovery.

Histopathological analysis confirmed a cystic lymphangioma.

\section{Discussion}

The majority of lymph from the lower part of the body is transported on the left side of the body via the thoracic duct. This enters the neck on the left and terminates at the junction of the left subclavian and jugular veins. In contrast, on the right side of the body the main lymphatic channel is only $2-5 \mathrm{~mm}$ in length and is formed by the convergence of the right jugular, transverse cervical and subclavian lymph trunks. These drain the right side of the head and right upper limb only. Lymph flow is therefore lower than on the left side, and lymphocoeles are correspondingly less frequent. ${ }^{4}$

Traumatic lymphocoeles can be explained by weakening of the lymphatic duct wall, leading to expansion and cyst formation. Atraumatic lymphocoeles are more difficult to explain. Congenital weakness of the duct wall has been postulated as the reason for their formation in otherwise healthy individuals. ${ }^{3}$ In one other reported case of a right-sided, spontaneous, cervical lymphocoele, ${ }^{4}$ it was suggested that repeated movements acting upon a weakened duct wall lead to expansion into a cyst. In this case and in our first patient, the lesion arose after a non-contact exercise session at a fitness gym.

- Spontaneous cervical lymphocoeles are very rare, and present as a fluctuant, asymptomatic, cystic swelling in the neck of otherwise fit individuals

- Inadvertent surgical damage to these lesions can result in chyle leakage; some centres thus advocate conservative treatment such as sclerotherapy

- In the two cases presented, surgical excision proved to be straightforward and the cosmetic result was excellent

In cases of spontaneous cervical lymphocoele, simple needle aspiration of the cyst will yield clear or milky fluid, and biochemical analysis will confirm contents consistent with chylous fluid. Ultrasound and CT or MRI scanning may indicate the presence and position of a larger feeding vessel, and can also establish the extent of the lesion.

The position of these lesions within the neck results in a potential risk of surgical damage to major blood vessels, the accessory nerve, phrenic nerve and brachial plexus. In addition, any feeding lymphatic vessels may be thin-walled and difficult to recognise. Inadvertent damage to these could result in chyle leakage. Because of this, some centres advocate conservative treatment such as sclerotherapy. The literature suggests that, whilst sclerotherapy can be useful, it is far from universally successful, can require multiple treatments and may take many weeks to work. ${ }^{5,6}$

In our experience, sclerotherapy was not helpful. Surgical excision proved to be straightforward, and the cosmetic result in both cases was excellent. However, potential complications, including a chylous leak, must be explained in full before intervention.

\section{References}

1 Lecanu JB, Gallas D, Biacabe B, Bonfils P. Lymphocele of the thoracic duct presenting as a left supraclavicular mass: a case report and review of the literature. Auris Nasus Larynx 2001:28:275-277

2 Nouwen J, Halimi P, Hans S, Laccourreye O. Lymphocele after neck dissection. Ann Otol Rhinol Laryngol 2004:113:39-42

3 Hekiert A, Newman J, Sargent R, Weinstein G. Spontaneous cervical lymphocele. Head Neck 2007;29:77-80

4 Podbielski FJ, Rodriguez HE, Djohan RS, Connolly MM, Conlan AA. Spontaneous right cervicothoracic lymphocoele. J Thorac Cardiovasc Surg 2003;125:736-7

5 Kim KH, Sung MW, Roh JL, Han MH. Sclerotherapy for congenital lesions in the head and neck. Otolaryngol Head Neck Surg 2004;131:307-16

6 Bloom DC, Perkins JA, Manning SC. Management of lymphatic malformations. Curr Opin Otolaryngol Head Neck Surg 2004;12:500-4

Address for correspondence:

Ms Fiona MacGregor,

Department of Otolaryngology,

Gartnavel General Hospital,

Glasgow G12 0YN,

Scotland, UK.

Fax: 01412111671

E-mail: Fiona.MacGregor@ggc.scot.nhs.uk

Ms F MacGregor takes responsibility for the integrity

of the content of the paper.

Competing interests: None declared

\title{
Spontaneous cervical lymphocoele: case reports and management decisions - ERRATUM
}

\author{
F D L Walker, F B MacGregor, I Ganley
}

doi:10.1017/S0022215109990909, Published by Cambridge University Press, 19 August 2009.

The above paper ${ }^{1}$ was published online, prior to print publication, with the third author's name shown as above. This author's name should have appeared as 'I Ganly'.

\section{Reference}

1 Walker FDL, MacGregor FB, Ganley I. Spontaneous cervical lymphocoele: case reports and management decisions. $J$ Laryngol Otol 2010;124:549-551 